\title{
Redução da proteína da dieta com base no conceito de proteína ideal para tilápias-do-nilo (Oreochromis niloticus) criadas em tanques-rede
}

\author{
Daniele Botaro', Wilson Massamitu Furuya ${ }^{2}$, Lilian Carolina Rosa Silva ${ }^{3}$, Lilian Dena dos \\ Santos ${ }^{4}$, Tarcila Souza de Castro Silva ${ }^{5}$, Vivian Gomes dos Santos ${ }^{5}$ \\ ${ }_{1}$ Doutoranda do Programa de Pós-graduação em Biofísica Ambiental, IBCCF - Universidade Federal do Rio de Janeiro. \\ 2 Departamento de Zootecnia - Universidade Estadual de Maringá, Centro de Ciências Agrárias, Maringá-PR. \\ 3 Doutoranda do Programa de Pós-graduação em Zootecnia - Universidade Estadual de Maringá, Centro de Ciências Agrárias, Maringá-PR. \\ 4 Mestranda do Programa de Pós-graduação em Zootecnia - Universidade Estadual de Maringá, Centro de Ciências Agrárias, Maringá-PR. \\ ${ }^{5}$ Mestranda do Programa de Pós-graduação em Nutrição Animal da UNESP-FMVZ -Botucatu/SP.
}

RESUMO - Avaliou-se o desempenho de tilápias-do-nilo (Oreochromis niloticus) criadas em tanques-rede e alimentadas com dietas contendo 27,0 (controle); 25,2; 24,3 e 22,7\% de proteína digestível. Aminoácidos cristalinos (L-lisina, DL-metionina e L-treonina) foram adicionados à dieta considerando o conceito de proteína ideal e simulando o perfil de aminoácidos da dieta controle. Os peixes $(34,63 \pm 19 \mathrm{~g})$ foram alimentados manualmente com dietas isoenergéticas (3.075 kcal de energia digestível $/ \mathrm{kg}$ de dieta) até saciedade aparente, três vezes ao dia, durante 91 dias. Utilizou-se um delineamento inteiramente casualizado, com quatro tratamentos, três repetições e 25 peixes/unidade experimental. Não foram observados efeitos dos níveis de proteína digestível sobre o ganho de peso, a conversão alimentar, a taxa de eficiência protéica, o peso da carcaça eviscerada, o rendimento de carcaça, o peso e o rendimento de filé, a sobrevivência e o hematócrito. Houve efeito quadrático dos níveis de proteína digestível sobre o consumo; o maior valor foi estimado para a dieta contendo $24,41 \%$ de proteína digestível e excreção de nitrogênio, na qual o melhor resultado estimado foi obtido com peixes que receberam a dieta contendo $24,92 \%$ de PD. Com a redução nos níveis de proteína digestível, observou-se aumento linear na retenção de nitrogênio. É possível reduzir o nível de proteína digestível, de 27 (29,1\% de PB) para 24,3\% (26,6\% de PB), em dietas para tilápias-do-nilo criadas em tanques-rede. Essa redução deve ser feita por meio da suplementação de aminoácidos (com base no conceito de proteína ideal), considerando o desempenho e o custo da dieta/kg ganho em filé.

Palavras-chave: aminoácidos, excreção de nitrogênio, proteína ideal

\section{Dietary protein reduction based on ideal protein concept for Nile Tilapia (Oreochromis niloticus) cultured in net pens}

\begin{abstract}
This study was carried out to evaluate the performance of Nile tilapia, cultured in net pens, and fed diets containing 27.0 (control), 25.2, 24.3, and 22.7\% of digestible protein. Crystalline amino acids (L-lysine, DL-methionine and L-threonine) were added to keep amino acid levels according to the ideal protein profile and to simulate amino acid levels of the control diet. Fish $(34.63 \pm 1.19 \mathrm{~g})$ were hand-fed one of the four isoenergetic (3,075 kcal of digestible energy/kg, as fed basis) experimental diets until apparent satiation, three times a day during 90 days. A completely randomized design with four treatments, three replicates and 25 fishes per experimental unit was utilized. No effects of dietary digestible protein levels on weight gain, feed conversion, protein efficiency ratio, empty carcass weight, carcass yield, fillet weight and yield, survival, and hematocrit were observed. It was observed quadratic effect on feed intake and nitrogen excretion, wich increased up to 24.41 and $24.92 \%$ of dietary digestible protein, respectively. The reduction of digestible protein levels resulted in a linear increase of nitrogen retention. It was concluded that it is possible to reduce the dietary digestible protein from $27.0(29.1 \%$ of $\mathrm{CP}$ ) to $24.3 \%$ (26.6\% of $\mathrm{CP}$ ) in amino acid supplemented diets (based on ideal protein concept), for juvenile Nile tilapia, cultured in net pens, without adverse effects on growth performance, carcass yield and composition, hematological parameters and cost of diet $/ \mathrm{kg}$ of fillet gain.
\end{abstract}

Key Words: amino acid, ideal protein, nitrogen excretion

\section{Introdução}

A tilápia-do-nilo (Oreochromis niloticus) é uma das espécies mais promissoras para a piscicultura, pelo rápido crescimento em sistema intensivo, pela rusticidade e por possuir carne com boas características organolépticas e filé sem espinhos intramusculares. $\mathrm{O}$ aumento na produtividade dessa espécie requer dietas balanceadas, pois o 
alimento natural não é capaz de atender às exigências dos peixes, principalmente quando criados em tanques-rede $\mathrm{e}$ raceways, onde a elevada biomassa por área e as deficiências ou os desbalanços de nutrientes podem acarretar perdas de produtividade e, conseqüentemente, menor retorno econômico.

Nas dietas dos peixes, a proteína é o item que mais influencia o custo de produção. Dietas formuladas com base na PB podem apresentar conteúdo de aminoácidos superior ao exigido pelos animais, que não possuem exigência de proteína, mas de uma proporção adequada de aminoácidos para a formação de proteína muscular e de outras proteínas corporais.

A exigência de proteína pela tilápia tem sido determinada por diversos autores. Pezzato et al. (1986) e Silva et al. (1989), em experimentos com alevinos de tilápia-do-nilo, encontraram exigências de 28 e $34 \%$ de PB, respectivamente. Al Hafedh (1999), avaliando diferentes níveis de proteína em quatro fases de crescimento desta espécie, determinaram exigência de $30 \%$ de $\mathrm{PB}$ para esses peixes na fase adulta. Furuya et al. (2000) e El-Saidy \& Gaber (2005) constataram exigência de 32 e $25 \%$ de $\mathrm{PB}$, respectivamente, para alevinos e juvenis dessa espécie.

Com o propósito de reduzir o conteúdo de proteína em dietas para peixes, nutricionistas têm buscado fontes alternativas de proteína e/ou a suplementação de aminoácidos na forma sintética. Os resultados obtidos com aminoácidos sintéticos parecem estar estreitamente relacionados aos alimentos utilizados, aos seus níveis de inclusão e ao valor nutricional de seus aminoácidos (Sadiku \& Jauncey, 1995). Assim, os aminoácidos sintéticos devem ser empregados para obtenção de dietas com adequadas proporções de aminoácidos, de forma a maximizar a utilização da proteína da dieta.

Em dietas formuladas com base na proteína do farelo de soja, a melhora no desempenho ocorre somente quando a lisina é suplementada juntamente com outros aminoácidos essenciais, como observado em tilápias-do-nilo por Odum \& Ejike (1991) e Furuya et al. (2004a); em salmão-do-atlântico (Salmo salar) por Olli et al. (1995) e Berge et al. (2002); e na truta arco-íris (Oncorhynchus mykiss) por Davies \& Morris (1997) e Yamamoto et al. (2005).

A formulação de dietas com menor nível protéico por meio da suplementação de aminoácidos sintéticos possibilita a formulação de dietas com valores mais próximos às exigências dos peixes. A relação entre os aminoácidos é fundamental para a melhor eficiência de utilização da proteína dietética.

O conceito de proteína ideal preconiza o balanço exato de aminoácidos, utilizando a lisina como aminoácido referência e estabelecendo sua proporção em relação aos demais aminoácidos essenciais, de forma a se obter um perfil ideal de aminoácidos que atenda às exigências de mantença e produção dos peixes. A aplicação desse conceito pode ser adaptada a uma variedade de situações, pois ainda que as exigências absolutas de aminoácidos possam mudar por diversas razões, as proporções permanecem praticamente estáveis.

A utilização do conceito de proteína ideal pode reduzir o conteúdo de proteína nas dietas, os custos de produção e a excreção de nitrogênio pelos peixes, um dos nutrientes mais poluentes no meio aquático, principalmente nas criações intensivas.

Este trabalho foi realizado com o objetivo de avaliar a redução do nível de proteína em dietas para tilápias-do-nilo criadas em tanques-rede, por meio da aplicação do conceito de proteína ideal, com base no desempenho, nas características hematológicas e na análise econômica.

\section{Material e Métodos}

O experimento foi realizado por meio da Universidade Estadual de Maringá, na chácara Hikari, em Paiçandu - PR, no período de janeiro a abril de 2004 .

Aproximadamente 4.000 alevinos revertidos, com peso vivo de 0,5 $\pm 0,1 \mathrm{~g}$, originados da Piscicultura Araucária Belmonte, Rolândia-PR, foram distribuídos em três hapas de náilon (malha de $2 \mathrm{~mm}$ ), com volume unitário útil de $6 \mathrm{~m}^{3}$, durante dois meses, onde foram alimentados com dieta comercial farelada, com $32 \%$ de PB.

Trezentos peixes com peso inicial de $34,63 \pm 1,19 \mathrm{~g}$ foram selecionados manualmente de acordo com o peso e distribuídos em 12 tanques-rede construídos com malha de $12 \mathrm{~mm}$ (fio multifilamento 210/24) com 1,2 × 1,0 × 2,0 m e volume útil unitário de $2,0 \mathrm{~m}^{3}$. Os tanques foram cobertos com rede de polietileno para proteção contra pássaros.

Foram avaliadas quatro dietas (Tabela 1) formuladas com diferentes níves de proteína digestível: $27,0=$ dieta controle com $27,0 \%$ de proteína digestível, suplementada com aminoácidos de modo a apresentar a relação lisina/ aminoácidos essenciais (metionina, metionina + cistina e treonina) determinada por Santiago \& Lovell (1988) para as tilápias; $25,2=$ dieta com $25,2 \%$ de proteína digestível (redução de 5\% no conteúdo de proteína digestível), com mesma quantidade e proporção de aminoácidos da dieta controle; $24,3=$ dieta com $24,3 \%$ de proteína digestível (redução de $10 \%$ no conteúdo de proteína digestível), com mesma quantidade e proporção de aminoácidos da dieta controle; $22,7=$ dieta com $22,7 \%$ de proteína digestível (redução de $15 \%$ no conteúdo de proteína digestível), com 
mesma quantidade e proporção de aminoácidos da dieta controle. As dietas foram balanceadas de acordo com os valores de proteína e aminoácidos digestíveis determinados por Furuya et al. (2001).

Todos os ingredientes foram moídos até diâmetro igual ou inferior a $0,50 \mathrm{~mm}$. As dietas foram granuladas (diâmetro de $4 \mathrm{~mm}$ ) por meio de extrusor na Fazenda Experimental de Iguatemi - FEI e desidratadas em estufa de ventilação forçada a $50^{\circ} \mathrm{C}$ durante 8 horas. A ração diária total foi distribuída três vezes/dia, às 8,12 e 18h, por meio de arraçoamento manual até saciedade aparente, quando não se observaram mais captura e regurgitação dos grânulos pelos peixes.
Todos os peixes foram pesados em balança digital $(0,01 \mathrm{~g})$ no início e ao final do experimento para determinação do ganho de peso, da conversão alimentar e das taxas de eficiência protéica e sobrevivência. Após pesagem, cinco peixes de cada unidade experimental foram devolvidos aos respectivos tanques para posterior análise hematológica. Os demais peixes foram acondicionados em caixa isotérmica com gelo e eviscerados para análises das características de carcaça (peso da carcaça eviscerada, peso dos filés e rendimento de filé) e do índice hepatossomático.

O rendimento de carcaça foi calculado como a razão entre o peso da carcaça eviscerada e o peso vivo após jejum

Tabela 1 - Composição percentual das dietas (na matéria natural)

Table 1 - Percentage composition of the experimental diets (as fed basis)

\begin{tabular}{|c|c|c|c|c|}
\hline \multirow[t]{2}{*}{$\begin{array}{l}\text { Ingrediente } \\
\text { Ingredient }\end{array}$} & \multicolumn{4}{|c|}{$\begin{array}{c}\text { Proteína digestível }(\%) \\
\text { Digestible protein }\end{array}$} \\
\hline & 27,00 & 25,20 & 24,30 & 22,70 \\
\hline Milho (Corn) & 26,49 & 30,25 & 33,96 & 37,84 \\
\hline Farelo de soja (Soybean meal) & 55,00 & 51,00 & 47,00 & 43,00 \\
\hline Farelo de trigo (Wheat meal) & 12,00 & 12,00 & 12,00 & 12,00 \\
\hline Fosfato bicálcico (Dicalcium phosphate) & 2,00 & 2,00 & 2,00 & 2,00 \\
\hline Óleo de soja (Soybean oil) & 3,00 & 3,00 & 3,00 & 3,00 \\
\hline L-lisina (L-lysine) & 0,00 & 0,12 & 0,24 & 0,35 \\
\hline DL-metionina (DL-methionine) & 0,17 & 0,24 & 0,30 & 0,31 \\
\hline L-treonina (L-threonine) & 0,12 & 0,17 & 0,28 & 0,28 \\
\hline Suplemento mineral e vitamínico ${ }^{1}$ (Min. and vit. mix) & 0,50 & 0,50 & 0,50 & 0,50 \\
\hline Vitamina $\mathrm{C}^{2}($ Vitamin $C)$ & 0,10 & 0,10 & 0,10 & 0,10 \\
\hline B HT & 0,02 & 0,02 & 0,02 & 0,02 \\
\hline Alginato de sódio (Sodium alginate) & 0,10 & 0,10 & 0,10 & 0,10 \\
\hline Sal (Salt) & 0,50 & 0,50 & 0,50 & 0,50 \\
\hline Total & 100 & 100 & 100 & 100 \\
\hline Custo da dieta $(\mathrm{R} \$ / \mathrm{kg})$ (Diet cost) & 0,609 & 0,612 & 0,619 & 0,613 \\
\hline \multicolumn{5}{|l|}{$\begin{array}{l}\text { Composição determinada } \\
\text { Analyzed composition }\end{array}$} \\
\hline $\operatorname{MS}(\%)^{3}(D M)$ & 92,77 & 92,66 & 92,75 & 92,68 \\
\hline $\mathrm{ED}(\mathrm{kcal} / \mathrm{kg})^{3}(D E)$ & 3085 & 3075 & 3070 & 3070 \\
\hline $\mathrm{PB}(\%)^{3}(C P)$ & 29,05 & 27,55 & 26,56 & 24,54 \\
\hline Proteína digestível $(\%)^{3}$ (Digestible protein) & 26,98 & 25,17 & 24,25 & 22,71 \\
\hline $\mathrm{E} / \mathrm{P}$ (kcal de ED/ \%PB) & 106 & 112 & 116 & 125 \\
\hline $\mathrm{P} / \mathrm{E}$ (kcal de ED/ \%PD) & 114 & 122 & 127 & 135 \\
\hline $\mathrm{EE}(\%)^{3}$ & 4,19 & 4,15 & 4,12 & 4,07 \\
\hline FB $(\%)^{3}(C F)$ & 4,94 & 4,75 & 4,56 & 4,36 \\
\hline $\mathrm{Ca}(\%)^{3}$ & 0,63 & 0,62 & 0,61 & 0,60 \\
\hline Fósforo disponível $(\%)^{3}$ (Available phosphorus) & 0,56 & 0,55 & 0,54 & 0,52 \\
\hline \multicolumn{5}{|l|}{ Aminoácidos digestíveis $(\%)^{4}$ (Digestible amino acids) } \\
\hline Lisina $^{4}$ (Lysine) & 1,51 & 1,51 & 1,51 & 1,50 \\
\hline Metionina $^{4}$ (Methionine) & 0,57 & 0,62 & 0,66 & 0,66 \\
\hline Metionina + cistina $^{4}$ (Methionine + cystine $)$ & 1,00 & 1,11 & 1,03 & 1,00 \\
\hline Treonina $^{4}$ (Threonine) & 1,12 & 1,12 & 1,19 & 1,12 \\
\hline Triptofano $^{4}$ (Thryptophan) & 0,48 & 0,51 & 0,62 & 0,65 \\
\hline Arginina $^{4}$ (Arginine) & 2,21 & 2,08 & 1,97 & 1,83 \\
\hline
\end{tabular}

1 Suplemento mineral e vitamínico (vitamin and mineral mix) (Supremais): composição por kg do produto (composition per $\mathrm{kg}$ of product): vit. A = 1200.000 Ul; vit. $\mathrm{D} 3=200.000 \mathrm{UI}$; vit. $\mathrm{E}=12.000 \mathrm{mg}$; vit. $\mathrm{K} 3=2.400 \mathrm{mg}$; vit. B1 = $4.800 \mathrm{mg}$; vit. $\mathrm{B} 2=4.800 \mathrm{mg} ;$ vit. $\mathrm{B} 6=4.000 \mathrm{mg} ;$ vit. B12 = $4.800 \mathrm{mg}$; ác. fólico $($ folic acid $)=1.200 \mathrm{mg}$; pantotenato de Ca (calcium pantothenic) $=12.000 \mathrm{mg}$; vitamina C (vitamin C) $=48.000 \mathrm{mg}$; biotina (biotin) = $48 \mathrm{mg}$; colina (choline) $=65.000 \mathrm{mg}$; niacina $($ niacin $)=24.000 \mathrm{mg} ; \mathrm{Fe}=10.000 \mathrm{mg} ; \mathrm{Cu}=600 \mathrm{mg} ; \mathrm{Mg}=4.000 \mathrm{mg} ; \mathrm{Zn}=6.000 \mathrm{mg} ; \mathrm{I}=20 \mathrm{mg} ; \mathrm{Co}=2 \mathrm{mg}$ e Se $=20 \mathrm{mg} ;$

2 Vitamina C (vitamin C): (42\% de ácido ascórbico) (42\% of ascorbic acid).

3 Valores calculados de acordo com Pezzato et al. (2002) (Calculated according to Pezzato et al., 2002).

4 Valores calculados de acordo com Furuya et al. (2001) (Calculated according to Furuya et al., 2001). 
de 24 horas, enquanto o rendimento de filés correspondeu à razão entre o peso dos filés e o peso vivo do animal. O índice hepatossomático foi determinado como a razão entre o peso do fígado e o peso vivo do peixe.

Para as análises hematológicas, foram utilizados cinco peixes/repetição ao final do período experimental. Os peixes foram anestesiados (benzocaína, $1 \mathrm{~g} / 15 \mathrm{~L}$ de água) e, após completa dessensibilização, foi realizada coleta de sangue por punção da veia caudal com seringa de $3 \mathrm{~mL}$ banhada com o anticoagulante EDTA a 3\%. A concentração de hemoglobina foi determinada pelo método da cianometahemoglobina, utilizando-se kit comercial Hemoglobina Analisa Diagnóstica ${ }^{\circledR}$, para determinação colorimétrica em espectrofotômetro de absorção atômica. O hematócrito foi obtido pelo método do microhematócrito. As variáveis supracitadas foram avaliadas utilizando-se as técnicas descritas por Jain (1986). As amostras de sangue foram centrifugadas a $3.000 \mathrm{rpm}$, durante cinco minutos, para leitura em tabela de \% de hematócrito. As análises foram realizadas no Laboratório de Nutrição de Animal do Departamento de Zootecnia da Universidade Estadual de Maringá.

A cada quatro dias, foram tomadas as medidas de temperatura ( 8 e $16 \mathrm{~h})$, $\mathrm{pH}$ e oxigênio dissolvido $(\mathrm{mg} / \mathrm{L})$ da água do tanque. Os dados foram obtidos utilizando-se kit digital portátil.

Para determinação dos coeficientes de digestibilidade, foram utilizadas 15 tilápias-do-nilo do lote mantido em hapas no mesmo tanques-rede, com peso médio de $132,5 \pm 13,3 \mathrm{~g}$. As tilápias foram mantidas em dois aquários de fibra de vidro, com volume útil de $180 \mathrm{~L}$ para a coleta de fezes.

O sistema foi mantido sob aeração constante por meio de pedra porosa acoplada a um soprador central, para manter o oxigênio entre 4 a $6 \mathrm{mg} / \mathrm{L}$. A temperatura da água foi mantida entre $25 \mathrm{e} 27^{\circ} \mathrm{C}$. Esses parâmetros foram aferidos diariamente, às 8 e $17 \mathrm{~h}$, em oxímetro digital portátil para leitura do oxigênio dissolvido e da temperatura.

A renovação de água dos aquários de coleta de fezes foi feita diariamente ( $8 \mathrm{~h} 30$ e 17h30) utilizando-se a água proveniente de um reservatório de $1.000 \mathrm{~L}$ com água mantida nas mesmas condições dos aquários de digestibilidade. Os peixes foram arraçoados diariamente das 7 às $9 \mathrm{~h}$ e das 13 às 17h, manualmente, até saciedade aparente.

Para determinação dos CDA, as dietas utilizadas no experimento de desempenho foram moídas e adicionadas de $0,1 \%$ de óxido crômico $\left(\mathrm{Cr}_{2} \mathrm{O}_{3}\right)$ como indicador, sendo peletizadas em moinho manual e desidratadas em estufa de ventilação forçada a $50^{\circ} \mathrm{C}$, conforme recomendado por Pezzato et al. (2002).
A coleta de fezes foi realizada diariamente às $8 \mathrm{e} 17 \mathrm{~h}$, durante cinco dias, para formar um pool de amostras de cada aquário, que foi considerado repetição. Para a troca de dieta, foi estabelecido um intervalo de cinco dias para adaptação. O material coletado foi desidratado em estufa de ventilação forçada (a $55^{\circ} \mathrm{C}$, durante 48 horas), sendo triturado em moinho faca, identificado e armazenado em refrigerador para posterior análise.

Os coeficientes de digestibilidade da energia e PB das dietas foram determinados de acordo com a expressão proposta por Nose (1960).

A retenção de nitrogênio foi calculada de acordo com a expressão:

$$
\mathrm{ERN}=\frac{\mathrm{Nf} . \mathrm{Pf}-\mathrm{Ni} . \mathrm{Pi}}{\mathrm{Nc}} .100
$$

em que: ERN = eficiência de retenção de nitrogênio (\%); $\mathrm{Nf}=$ nitrogênio final $(\%) ; \mathrm{Pf}=$ peso final $(\mathrm{g}) ; \mathrm{Ni}=$ nitrogênio inicial (\%); $\mathrm{Pi}=$ peso inicial $(\mathrm{g}) ; \mathrm{Nc}=$ nitrogênio consumido (g).

A excreção de nitrogênio fecal foi determinada segundo a expressão:

$$
\mathrm{Ne}=\frac{\mathrm{Nc}-(\text { Nc.CDAn })}{\mathrm{GP}} \cdot 1000
$$

em que: $\mathrm{N}_{\mathrm{e}}=$ nutriente excretado $(\mathrm{kg} / \mathrm{t}$ de peixe $) ; \mathrm{N}_{\mathrm{c}}=$ nutriente consumido $(\mathrm{kg}) ; \mathrm{CDA}_{\mathrm{n}}=$ coeficiente de digestibilidade aparente do nutriente (\%); GP = ganho de peso $(\mathrm{kg})$.

Para determinação da excreção do N, a PB da dieta foi convertida em $\mathrm{N}$ e o valor de $\mathrm{PB}$ da dieta, dividido por 6,25.

As análises químico-bromatológicas das dietas, das carcaças e das fezes foram realizadas no Laboratório de Análise de Alimentos do Departamento de Zootecnia da Universidade Estadual de Maringá - UEM, conforme metodologia descrita por Silva \& Queiroz (2002).

Os dados foram submetidos às análises de variância e regressão polinomial, por meio do programa SAEG - Sistemas de Análises Estatísticas e Genéticas (Euclydes, 1983).

\section{Resultados e Discussão}

Os valores médios obtidos para a temperatura e o oxigênio dissolvido da água dos tanques-rede foram $28,55 \pm 1,72^{\circ} \mathrm{C}$ e $5,72 \pm 1,09 \mathrm{mg} / \mathrm{L}$, respectivamente. Os parâmetros permaneceram dentro da faixa recomendada por Popma \& Green (1990) para adequado desempenho de tilápias.

Na Tabela 2 encontram-se os valores médios de desempenho de tilápias-do-nilo criadas em tanques-rede alimentadas com dietas contendo diferentes níveis de proteína digestível. 
Não houve efeito da redução dos níveis de proteína digestível sobre o ganho de peso, a conversão alimentar, a taxa de eficiência protéica, o peso da carcaça eviscerada, o rendimento de carcaça e o peso e rendimento de filé. Não foi observada mortalidade durante o período experimental.

A suplementação adequada de aminoácidos possibilitou a redução do conteúdo de proteína digestível das dietas e não afetou o ganho de peso dos peixes, indicando que o perfil adequado de aminoácidos foi capaz de atender à exigência desta espécie. Os peixes alimentados com a dieta contendo 25,2 e $24,3 \%$ de proteína digestível obtiveram aumento de 10,13 e $6,51 \%$ no ganho de peso, respectivamente, em relação àqueles alimentados com a dieta controle. Ressalta-se que, com a utilização da dieta com menor valor de proteína digestível, o ganho de peso foi semelhante ao ganho dos peixes alimentados com a dieta controle (27\% PD).

Kim (1997), em estudo realizado com a truta arco-íris, avaliou dietas com 10, 15, 20, 25 e 35\% de PB e observou aumento linear $(\mathrm{P}<0,05)$ no ganho de peso dos peixes alimentados com a dieta contendo $25 \%$ de PB suplementada com arginina e metionina sintética. Em experimento com a mesma espécie, Cheng et al. (2003) utilizaram fonte de proteína de origem vegetal suplementada com aminoácidos e observaram que os peixes alimentados com a dieta com $37 \%$ de PB suplementada com aminoácidos sintéticos apresentaram maior taxa de crescimento em comparação àqueles alimentados com dieta contendo $42 \%$ de PB e mesmos valores de lisina, metionina, treonina e triptofano. Esses autores relataram ainda que a dieta com maior nível de lisina $(1,8 \%)$ promoveu maior crescimentos dos peixes.
Os dados de conversão alimentar obtidos neste estudo diferem dos descritos por Webb \& Gatlin (2003), ao avaliarem níveis de 35 e $45 \%$ de PB e formas de proteína (intacta e suplementada com aminoácidos) para "red drum" (Sciacrops ocellatus). Divergem ainda dos resultados obtidos por Berge et al. (2002), em estudo com salmão-doatlântico, no qual avaliaram as exigências de lisina e arginina e notaram melhora na conversão alimentar dos peixes alimentados com a dieta suplementada com aminoácido sintético.

Com a redução nos níveis de proteína digestível, observou-se efeito quadrático $(\mathrm{P}<0,05)$ do nível de proteína digestível no consumo, sendo estimado valor de $24,41 \%$ de PD para o maior consumo de alimento (Figura 1).

Yamamoto et al. (2005) observaram redução no consumo em experimento com truta arco-íris alimentada com dietas com menor valor protéico. Neste estudo, o maior consumo foi relacionado ao maior ganho de peso, pois a conversão alimentar permaneceu praticamente constante nos peixes alimentados com as dietas com 27; 25,2 e 24,3\% de PD.

Não foi observado efeito dos tratamentos sobre a taxa de eficiência protéica. Por outro lado, houve aumento linear $(\mathrm{P}<0,05)$ da retenção de nitrogênio à medida que se reduziu o conteúdo de proteína digestível (Figura 2).

O balanço de aminoácidos é importante para o máximo aproveitamento da proteína pelos peixes. Os resultados de retenção de nitrogênio neste estudo diferem dos obtidos por Yamada et al. (1981), Cowey \& Walton (1989) e Schumacher et al. (1997), que questionaram a eficiência de utilização dos aminoácidos sintéticos pelos peixes, pela rápida elevação dos aminoácidos sintéticos nos níveis

Tabela 2 - Desempenho de tilápias-do-nilo alimentadas com dietas formuladas com diferentes níveis de proteína digestível Table 2 - Performance of Nile tilapia fed diets with different digestible protein levels

\begin{tabular}{|c|c|c|c|c|c|}
\hline & \multicolumn{4}{|c|}{$\begin{array}{c}\text { Proteína digestível na dieta }(\%) \\
\text { Dietary digestible protein }\end{array}$} & \multirow[t]{2}{*}{$\mathrm{CV}^{1}$} \\
\hline & 27,00 & 25,20 & 24,30 & 22,70 & \\
\hline Peso inicial (g) (Start weight) & 36,40 & 34,76 & 33,39 & 34,13 & 1,56 \\
\hline Peso final (g) (End weight) & 253,55 & 273,90 & 264,67 & 251,91 & 7,83 \\
\hline Ganho de peso (g) (Weight gain) & 217,15 & 239,14 & 231,28 & 217,77 & 9,13 \\
\hline Consumo $(\mathrm{g} / \text { peixe })^{3}$ (Feed intake) & 365,44 & 400,05 & 385,56 & 385,01 & 1,16 \\
\hline Conversão alimentar (Feed conversion) & 1,69 & 1,68 & 1,68 & 1,77 & 9,16 \\
\hline Taxa de eficiência protéica (Protein efficiency ratio) & 2,05 & 2,17 & 2,26 & 2,31 & 8,92 \\
\hline Retenção de nitrogênio $(\%)^{2}$ (Nitrogen retention) & 34,80 & 38,91 & 41,45 & 42,40 & 10,26 \\
\hline Excreção de nitrogênio $(\mathrm{kg} / \mathrm{t})^{3}$ (Nitrogen excretion) & 5,60 & 6,41 & 6,21 & 5,18 & 9,24 \\
\hline Peso da carcaça (g) (Carcass weight) & 231,65 & 251,96 & 241,39 & 229,56 & 7,54 \\
\hline Rendimento de carcaça $(\%)$ (Carcass yield) & 90,43 & 92,03 & 91,17 & 91,13 & 1,26 \\
\hline Peso do filé (g) (Fillet weight) & 91,34 & 101,88 & 98,11 & 89,93 & 9,45 \\
\hline Rendimento de filé (\%) (Fillet yield) & 39,06 & 40,49 & 40,51 & 39,14 & 3,92 \\
\hline Índice hepatossomático (Hepatosomatic index) & 1,86 & 1,76 & 1,66 & 1,97 & 8,94 \\
\hline
\end{tabular}




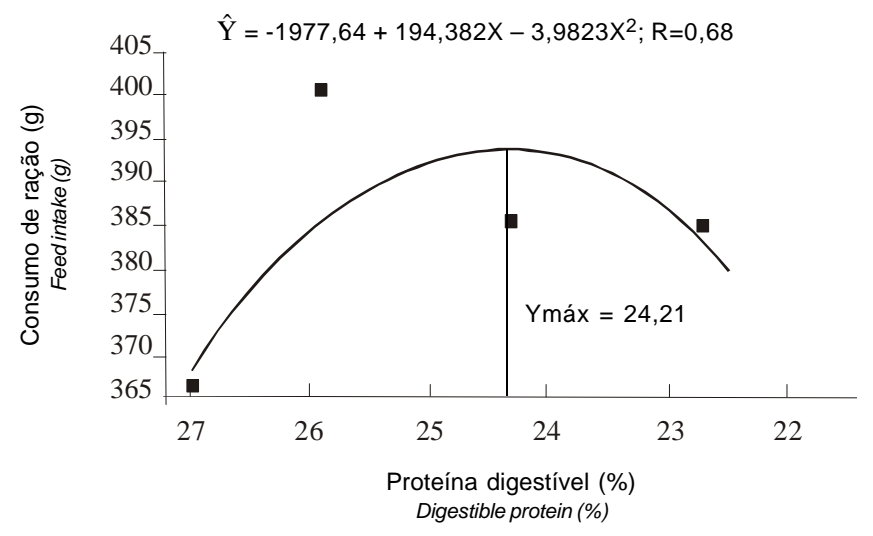

Figura 1 - Consumo de ração por tilápias-do-nilo alimentadas com dietas formuladas com diferentes níveis de proteína digestível.

Figure 1 - Feed intake of Nile tilapia fed diets with different digestible protein levels.

plasmáticos e pelas perdas por catabolismo (Plakas \& Katayama, 1981; Murai et al., 1985).

Outro fator que pode influenciar a utilização dos aminoácidos sintéticos pelos peixes está relacionado à alta taxa de lixiviação, como observado por Zarate \& Lovell (1997), que constataram lixiviação de 13\% da lisina sintética da dieta 15 segundos após o contato com a água, enquanto apenas $2 \%$ da lisina ligada à proteína foi lixiviada. Nesta pesquisa, adotou-se maior freqüência de arraçoamento (3 vezes/dia) para evitar a rápida elevação nos níveis plasmáticos de lisina, metionina e treonina e aumentar a eficiência de utilização da proteína. O mesmo foi observado por Tantikitti \& March (1995) e Berge et al. (2002), respectivamente, em trabalhos realizados com a truta arco-íris e com o salmão-do-atlântico.

As relações energia:proteína e lisina:arginina são importantes para adequada utilização dos aminoácidos. Neste estudo, os melhores resultados de desempenho foram obtidos com as dietas contendo relação energia digestível:proteína digestível de 122:1 e 127:1 e relação lisina digestível:arginina digestível de 0,72:1 e 0,77:1, com as dietas contendo 25,2 e 24,3\% de PD, respectivamente.

Kaushik et al. (1988), em estudo realizado com truta arco-íris, relataram que o aumento no conteúdo de arginina na dieta aumentou a digestibilidade desse aminoácido e diminuiu a digestibilidade da lisina, indicando que há competição entre esses aminoácidos para absorção no intestino delgado. Berge et al. (2002), em estudo realizado com salmão-do-atlântico, observaram que o crescimento e a conversão melhoraram nos peixes alimentados com dietas contendo níveis limitantes de lisina e altos níveis de arginina. Porém, nas dietas com níveis limitantes de arginina e altos

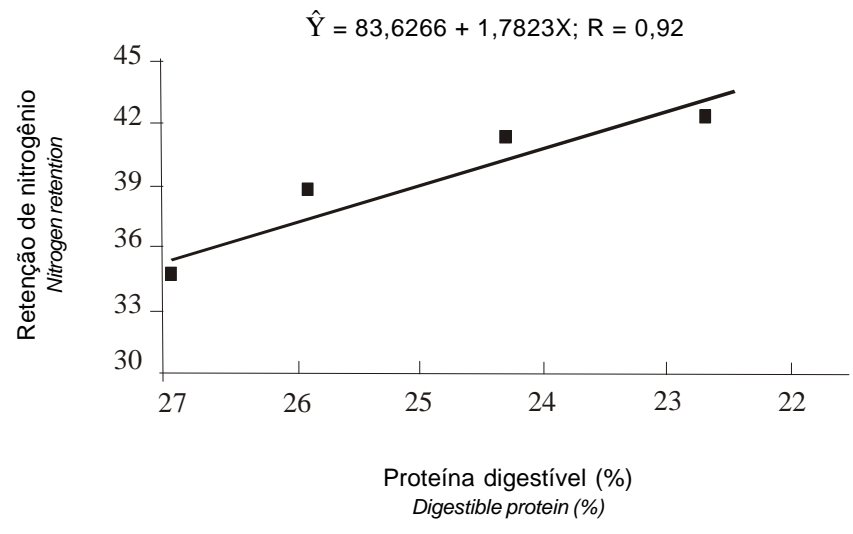

Figura 2 - Retenção de nitrogênio em tilápias-do-nilo alimentadas com dietas formuladas com diferentes níveis de proteína digestível.

Figure 2 - Nitrogen retention of Nile tilapia fed diets with different digestible protein levels.

níveis de lisina, não foi observada melhora no crescimento dos peixes. Neste estudo, em todas as dietas, os níveis de arginina mantiveram-se acima das exigências descritas pelo NRC (1993) para as tilápias.

Verificou-se efeito quadrático $(\mathrm{P}<0,05)$ dos níveis de proteína digestível na excreção de nitrogênio fecal, sendo estimado o valor de $24,93 \%$ de PD para a maior excreção de nitrogênio fecal (Figura 3).

Em experimento com carpa-maior-da-índia (Labeo rohita), Chakraborty \& Chakraborty (1998) observaram aumento na excreção de amônia com o aumento da proteína ingerida por esses peixes. Engin \& Carter (2001), em estudo com juvenis de enguia (Anguilla australis), observaram aumento da taxa de excreção de amônia com níveis mais altos de proteína na dieta. Os resultados obtidos neste experimento confirmaram os encontrados por Webb \& Gatlin (2003), que observaram redução na excreção de amônia em "red drum" alimentados com dietas com menor teor de proteína.

Viola \& Lahan (1991) observaram menor excreção de nitrogênio pela carpa comum alimentada com dieta contendo $25 \%$ de PB em comparação a uma dieta com $30 \%$ de PB. A excreção foi ainda menor nos peixes alimentados com a dieta com $25 \%$ de PB suplementada com lisina e metionina. Esses resultados estão de acordo com os encontrados por Rodehutscord et al. (1994), em estudo realizado com truta arco-íris. Esses autores observaram ser possível reduzir em $16 \%$ a excreção de nitrogênio em dietas contendo glúten de milho e suplementadas com aminoácidos sintéticos.

Cheng et al. (2003), em estudo com truta arco-íris, observaram que a dieta com $37 \%$ de PB (fonte vegetal) resultou em menor descarga de nitrogênio amoniacal total 


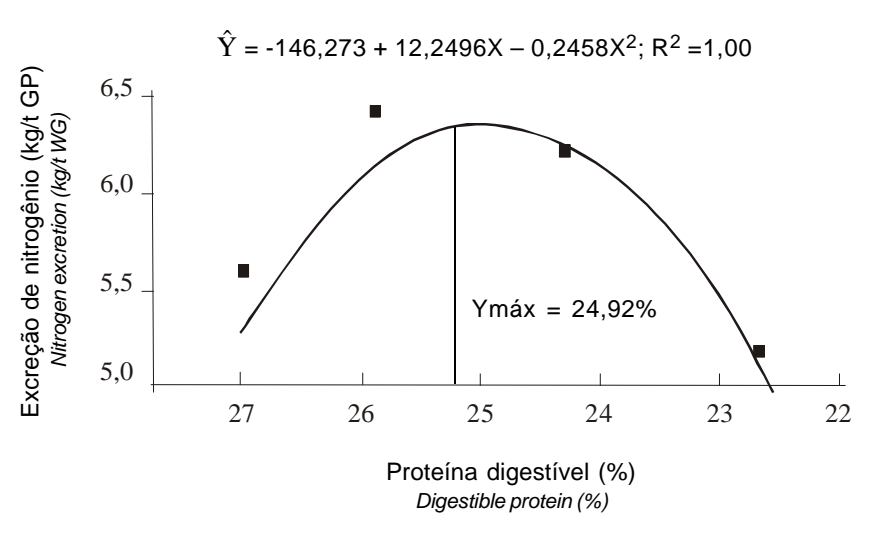

Figura 3 - Excreção de nitrogênio em tilápias-do-nilo alimentadas com dietas formuladas com diferentes níveis de proteína digestível.

Figure 3 - Nitrogen excretion of Nile tilapia fed diets with different digestible protein levels

pelos peixes em relação àquela com mesmo conteúdo de proteína, formulada com base na farinha de peixe. Esses autores observaram ainda que, em dietas contendo fonte vegetal de proteína e suplementada com aminoácidos sintéticos, a excreção de nitrogênio foi reduzida em $26 \%$ em comparação à excreção observada com a dieta contendo farinha de peixe.

Neste estudo, não houve efeito dos níveis de proteína digestível sobre o hematócrito e taxa de hemoglobina (Tabela 3). À exceção do valor de hemoglobina encontrado nos peixes alimentados com a dieta contendo $22,7 \%$ de PD, os dados de hematócrito e hemoglobina neste estudo foram superiores às médias dos valores descritos por Tavares-Dias \& Moraes (2004), de 28,58\% e 7,97 g/dL, respectivamente, em trabalhos realizados com tilápias-donilo em cativeiro.

O conteúdo de proteína das dietas não influenciou o peso e rendimento de carcaça e de filé. No entanto, nos peixes alimentados com a dieta contendo $25,2 \%$ de PD obtiveram-se maiores rendimentos de carcaça $(1,6 \%)$ e de filé $(1,43 \%)$ em relação àqueles alimentados com a dieta controle. Os maiores rendimentos de carcaça e de filé provavelmente estiveram relacionados à suplementação de lisina, metionina e treonina, utilizados para a síntese de tecido muscular, conforme explicado por Bailey (1989).

Como demonstrado na Tabela 4, não houve efeito dos níveis de proteína digestível sobre a composição química da carcaça. Os resultados dos trabalhos realizados com dietas contendo diferentes níveis de proteína não comprovam efeito sobre a composição da carcaça dos peixes, ao contrário de quando a proteína foi avaliada juntamente com níveis de energia, como observado por Lee \& Kim (2001), Allan \& Booth (2004) e Bechara et al. (2005), em estudos
Tabela 3 - Valores médios de hematócrito e hemoglobina em tilápias-do-nilo alimentadas com dietas com diferentes níveis de proteína digestível

Table 3 - Average values for hematocrit and hemoglobin of Nile tilapia fed diets with different digestible protein levels

\begin{tabular}{lrrrrr}
\hline & \multicolumn{3}{c}{$\begin{array}{c}\text { Proteína digestível na dieta }(\%)^{1} \\
\text { Dietary digestible protein }\end{array}$} & \multirow{2}{*}{$\mathrm{CV}^{1}$} \\
\cline { 2 - 5 } & 27,00 & 25,20 & 24,30 & 22,70 & \\
\hline $\begin{array}{l}\text { Hematócrito (\%) } \\
\text { Hematocrit }\end{array}$ & 33,85 & 32,99 & 28,94 & 29,85 & 9,41 \\
$\begin{array}{l}\text { Hemoglobina }(\mathrm{g} / \mathrm{dL})^{2} \\
\text { Hemoglobin }\end{array}$ & 8,81 & 9,07 & 8,43 & 7,13 & 14,00 \\
\hline
\end{tabular}

${ }^{1}$ Coeficiente de variação (Coefficient of variation).

realizados com juvenis de salmão "masu", "silver perch" e pacu, respectivamente.

A deposição de gordura está estreitamente relacionada ao balanceamento de aminoácidos e à relação energia/ proteína da dieta. No entanto, deve-se considerar o peso dos peixes, pois espera-se que aqueles de maior peso apresentem maior conteúdo de gordura corporal. Neste estudo, ainda que os peixes alimentados com a dieta contendo $25,2 \%$ de PD tenham apresentado o maior peso final, esses peixes tiveram menor porcentagem de gordura nos filés.

Na Tabela 5 encontram-se os valores médios de custo em dieta por quilo de ganho de peso e o custo da dieta por quilo de ganho em filé de tilápias-do-nilo alimentadas com dietas contendo diferentes níveis de proteína digestível criadas em tanques-rede. A redução do conteúdo de proteína digestível não influenciou o custo/kg de ganho de peso e o custo/kg de ganho em filé.

O aumento na suplementação de aminoácidos sintéticos resultou em elevação no custo do quilograma da dieta. Por outro lado, quando considerados o custo em dieta por quilograma de ganho de peso e o custo em dieta por quilograma de ganho de peso em filés, a relação custo/benefício permaneceu praticamente constante, à exceção do custo $/ \mathrm{kg}$ ganho em filé obtido para os peixes alimentados com a dieta contendo 22,7\%. Em termos práticos, é possível considerar que a redução no tempo de abate pela obtenção de peixes com maior peso e maior rendimento de carcaça certamente resulta em maior benefício econômico ao produtor.

Comprovou-se a possibilidade de reduzir o valor de proteína digestível da dieta de tilápias de 27 para 24,3\% de $\mathrm{PD}$, sem prejuízos ao crescimento, à utilização da proteína da dieta, ao rendimento e à composição da carcaça, sem causar anemia aos peixes e sem alterar o custo da dieta/kg de ganho de peso vivo e em filés. Resultados semelhantes foram observados por Cheng et al. (2003) e Yamamoto et al. (2005) em estudos realizados com a truta arco-íris, que viabilizaram a redução de 42 para $37 \%$ de $\mathrm{PB}$ e de 45 para $31 \%$ 
Tabela 4 - Composição química da carcaça de tilápias-do-nilo alimentadas com dietas contendo diferentes níveis de proteína digestível

Table 4 - Carcass chemical composition of Nile tilapia fed diets with different digestible protein levels

\begin{tabular}{lrrrrr}
\hline $\begin{array}{l}\text { Variável } \\
\text { Variable }\end{array}$ & \multicolumn{3}{c}{$\begin{array}{c}\text { Proteína digestível na dieta }(\%)^{1} \\
\text { Dietary digestible protein }\end{array}$} & \multirow{2}{*}{ CV $^{1}$} \\
\cline { 2 - 5 } & 27,00 & 25,20 & 24,30 & 22,70 & \\
\hline Água (\%) (Water) & 76,29 & 77,31 & 76,40 & 76,63 & 1,06 \\
PB (\%) (CP) & 17,45 & 17,47 & 17,83 & 17,81 & 5,99 \\
Gordura (\%) (Fat) & 2,39 & 2,08 & 2,44 & 2,23 & 5,67 \\
Cinzas (\%) (Ash) & 1,09 & 0,99 & 1,12 & 1,14 & 6,70 \\
\hline
\end{tabular}

${ }^{1}$ Coeficiente de variação (Coefficient of variation).

de $\mathrm{PB}$, respectivamente, sem prejuízos ao desempenho. Além disso, esses autores verificaram redução na excreção de nitrogênio amoniacal pelos peixes alimentados com a dieta contendo menor teor de proteína.

A redução do teor de proteína nas dietas dos peixes é importante para diminuir o custo com alimentação. Além disso, diminui a excreção de nitrogênio na água, o que auxilia na produção sustentável de peixes, principalmente quando em condições de altas densidades, quando é necessário o fornecimento, exclusivamente, das dietas balanceadas.

Os resultados obtidos neste estudo comprovaram ser possível elaborar dietas balanceadas com redução de $10 \%$ no conteúdo de proteína digestível para tilápias-do-nilo. Esses resultados foram obtidos com o fornecimento de dietas suplementadas com aminoácidos (com base no conceito de proteína ideal), com valores de energia, proteína e aminoácidos digestíveis e fósforo disponível.

\section{Conclusões}

É possível reduzir o teor de proteína digestível de 27 (29,1\% de proteína bruta) para $24,3 \%$ (26,6\% de proteína bruta) em dietas para tilápias-do-nilo criadas em tanquesrede. Essa redução pode ser obtida por meio da suplementação de aminoácidos (com base no conceito de proteína ideal), considerando o desempenho dos peixes e a análise econômica do sistema de produção.

\section{Literatura Citada}

AL-HAFEDH, Y.S. Effects of dietary protein on growth and body composition of Nile tilapia, Oreochromis niloticus. Aquaculture Research, v.30, p.385-393, 1999

ALLAN, G.L.; BOOTH, M.A. The effects of dietary digestible protein and digestible energy content of protein retention efficiency of juvenile silver perch (Bidyanus bidyanus). Aquaculture, v.35, p.970-980, 2004.
Tabela 5 - Custo de produção de tilápias-do-nilo alimentadas com dietas formuladas com diferentes níveis de proteína digestível

Table 5 - Production cost of Nile tilapia fed diets with different digestible protein levels

\begin{tabular}{llllll}
\hline & \multicolumn{3}{c}{$\begin{array}{c}\text { Proteína digestível na dieta }(\%)^{1} \\
\text { Dietary digestible protein }\end{array}$} & \multirow{2}{*}{$\mathrm{CV}^{1}$} \\
\cline { 2 - 4 } & 27,00 & 25,20 & 24,30 & 22,70 & \\
\hline $\begin{array}{l}\text { Custo/kg de ganho } \\
\text { de peso (R } \$ / \mathrm{kg})\end{array}$ & 1,03 & 1,03 & 1,04 & 1,09 & 9,01 \\
$\begin{array}{l}\text { Cost/kg weight gain } \\
\text { Custo/kg de filé (R } \$ / \mathrm{kg}) \\
\text { Cost/kg fillet }\end{array}$ & 2,47 & 2,41 & 2,47 & 2,64 & 8,53 \\
\hline
\end{tabular}

${ }^{1}$ Coeficiente de variação (Coefficient of variation).

BAILEY, A.J. Molecular and fiber structure of collagen. In: BAILEY, A.J.; LIGHT, N.D. (Eds.) Connective tissue in meat and meals products. London: Elsevier, 1989. p.35-48.

BECHARA, J.A.; ROUX, J.P.; DIAZ, F.J.R. et al. The effect of dietary protein level on pond water quality and feed utilization efficiency of pacu Piaractus mesopotamicus. Aquaculture Research, v.36, p.546-553, 2005.

BERGE, G.E.; SUEIER, H.; LIED, E. Effects of feeding Atlantic salmon (Salmo salar) imbalanced levels of lysine and arginine. Aquaculture Nutrition, v.8, p.239-248, 2002.

CHAKRABORTY, S.C.; CHAKRABORTY, S. Effect of dietary protein level on excretion of ammonia in Indian major carp (Labeo rohita), fingerlings. Aquaculture Nutrition, v.4, p.4751, 1998.

CHENG, Z.J.; HARDY, R.W.; USRY, J.L. Plant protein ingredients with lysine supplementation reduce dietary protein level in rainbow trout (Oncorhynchus mykiss) diets, and reduce ammonia nitrogen and soluble phosphorus excretion. Aquaculture, v.218, p.553-565, 2003.

COWEY, C.B.; WALTON, M.J. Intermediary metabolism. In: HALVER, J.E. (Ed.) Fish nutrition. 2.ed. San Diego: Academic Press, 1989. p.259-329.

DAVIES, S.J.; MORRIS, P.C. Influence of multiple amino acids supplementation on the performance of rainbow trout, Oncorhynchus mykiss (Walbaum), fed soya based diets. Aquaculture Research, v.28, p.65-74, 1997

EL-SAYDI, D.M.S.D.; GABER, M.M.A. Effect of dietary protein levels and feeding rates on growth performance, production traits and body composition of Nile tilapia (Oreochromis niloticus), cultured in concrete tanks. Aquaculture Research, v.36, p.163-171, 2005

ENGIN, K.; CARTER, C.G. Ammonia and urea excretion rates of juveniles Australian short-finned eel (Anguilla australis australis) as influenced by dietary protein level. Aquaculture, v.194, p.123-136, 2001.

EUCLYDES, R.F. Manual de utilização do programa SAEG (Sistema para análises estatística e genética). Viçosa, MG: Universidade Federal de Viçosa, 1983. 59p.

FURUYA, W.M.; HAYASHI, C.; FURUYA, V.R.B. et al. Exigência de proteína para alevino revertido de tilápia do Nilo (Oreochromis niloticus). Revista Brasileira de Zootecnia, v.29, n.6, p.1912-1917, 2000.

FURUYA, W.M.; PEZZATO, L.E.; MIRANDA, E.C. et al. Coeficientes de digestibilidade e valores de aminoácidos digestíveis de alguns ingredientes pela tilápia do Nilo (Oreochromis niloticus). Revista Brasileira de Zootecnia, v.30, n.4, p.1125-1131, 2001

FURUYA, W.M.; SILVA, L.C.R.; NEVES, P.R. et al. Exigência de metionina+cistina para alevinos de tilápia do Nilo, Oreochromis niloticus. Ciência Rural, v.34, n.6, p.1933-1937, 2004a 
FURUYA, W.M.; BOTARO, D.; NEVES, P.R. Exigência de lisina pela tilápia do Nilo (Oreochromis niloticus) na fase de terminação. Ciência Rural, v.34, n.6, p.1933-1937, 2004b.

JAIN, N.C. Schalm's veterinary haematology. 4.ed. Philadelphia: Lea \& Febiger, 1986. 1221p.

JAUNCEY, K.; ROSS, B. A guide to tilapia feed and feeding. Scotland: University of Stirling, 1982. 111p.

KAUSHIK, S.J.; FAUCONNEAU, B.; TERRIER, L. et al. Arginine requirement and status assessed by different biochemical indices in rainbow trout Salmo gairdneri. Aquaculture, v.70, p.75-95, 1988

KIM, K-IL. Re-evaluation of protein and amino acid requirements of rainbow trout (Oncorhynchus mykiss). Aquaculture, v.151, p.3-7, 1997

LEE, S-M.; KIM, K-D. Effects of dietary protein and energy levels on the growth, protein utilizaion and body composition of juvenile masu salmon (Oncorhynchus masou). Aquaculture Research, v.32, p.39-45, 2001.

MURAI, T.; AKIYAMA, T.; WATANABE, T. et al. Effects of dietary protein and lipids levels on performance and carcass composition of fingerlings carp (Cyprinus carpo). Bulletin of the Japanese Society of Scientific Fisheries, v.54, p.605$608,1985$.

NATIONAL RESEARCH COUNCIL - NRC Nutrient requirements of warmwater fishes and shellfishes. Washington, D.C.: National Academy Press, 1993. 102p.

NOSE, T. On the digestion of food protein by gold-fish (Carassius auratus) L.) and rainbow trout (Salmo irideus G.). Bulletin Freshwater Fish Research Laboratory, v.10, p.11-22, 1960.

ODUM, O.; EJIKE, C. Aspects of amino acid utilization in the cichlid (Oreochromis niloticus). Acta Hidrobiology, v.33, p.345-352, 1991

OLLI, J.; KROGDAHL, A. Alcohol soluble components of soybean seem to reduce fat digestibility in fish-meal-based diets for Atlantic salmon (Salmo salar). Aquaculture Research, v.26, p.831-835, 1995.

PEZZATO, L.E.; PACKER. I.V.; PEZZATO, A.C. et al. Efeito de níveis de proteína sobre o crescimento da tilápia do Nilo (Oreochromis niloticus), submetida a reversão sexual. In: SIMPÓSIO BRASILEIRO DE AQUICULTURA, 5., 1986, Cuiabá. Anais... Cuiabá: 1986, p.70-71.

PEZZATO, L.E.; MIRANDA, E.C.; BARROS, M.M. et al. Digestibilidade aparente de ingredientes pela tilápia do Nilo (Oreochromis niloticus). Revista Brasileira de Zootecnia, v.31, n.4, p.1595-1604, 2002.

PLAKAS, S.M.; KATAYAMA, T. Apparent digestibilities of amino acids from three regions of the gastrointestinal tract of carp (Cyprinus carpo) after ingestion of a protein and corresponding free amino acid diet. Aquaculture, v.24, p.309-314, 1981.

POPMA, T.J.; GREEN, B.W. Sex reversal of tilapia in earthen ponds. Aquaculture production manual. Alabama: Alburn University, Alabama Research and Development, 1990. 15p. (Series 35).
RODEHUTSCORD, M.; BORCHERT, F.; GREGUS, Z. et al. Availability and utilization of free lysine in rainbow trout (Oncorhynchus mykiss). 2. Comparison of L-lysine $-\mathrm{HCl}$ and L-lysine sulphate. Aquaculture, v.187, p.177-183, 1994.

SADIKU, S.O.E.; JAUNCEY, K. Digestibility, apparent amino acid availability and waste generation potential of soybean flour: poultry meat blend based diets for tilapia, Oreochromis niloticus (L), fingerling. Aquacutlure Research, v.26, p.651-657, 1995.

SANTIAGO, C.B.; LOVELL, R.T. Amino acid requirements for growth of Nile tilapia. Journal of Nutrition, v.118, p.15401546, 1988.

SILVA, D.J; QUEIROZ, A.C. Análise de alimentos (métodos químicos e biológicos). 3.ed. Viçosa, MG: Universidade Federal de Viçosa, 2002. 235p

SILVA, S.S.; GUNASEKARA, R.M.; ATAPATU, D. The dietary protein requirements of young tilapia and an evaluation of the least cost of dietary protein levels. Aquaculture, v.80, p.271284, 1989.

SCHUHMACHER, A.; WAX, C.; GROPP, J.M. Plasma amino acids in rainbow trout (Oncorhynchus mykiss) fed intact protein or a crystalline amino acid diet. Aquaculture, v.151, p.15-28, 1997.

TANTIKITTI, C.; MARCH, B.E. Dynamics of plasma free amino acids in rainbow trout (Oncorhynchus mykiss) under variety of dietary conditions. Fish Physiology \& Biochemistry, v.14, p. 179-194, 1995.

TAVARES-DIAS, M.; MOURA, F.R.M. Hematologia de peixes teleósteos. 1.ed. Ribeirão Preto: 2004. 144p.

VIOLA, S.; LAHAN, E. Effects of lisyne supplementation in practical dcarp feeds on total protein sparing and reduction of pollution. The Israeli Journal of Aquaculture, v.43, p.112-1128, 1991.

WEBB, K.A.; GATLIN, D.M. Effects of dietary protein level and form on production characteristics and ammonia excretion of red drum Sciaenopss ocellatus. Aquaculture, v.225, p.17-26, 2003.

YAMADA, S.; SIMPSOM, K.; TANAKA, Y. et al. Plasma amino acid changes in rainbow trout force-fed casein and corresponding amino acid mixture. Bulletin of Japanese Society of Scientific Fisheries, v.47, p.1035-1040, 1981.

YAMAMOTO, T.; SUGITA, T.; FURUITA, H. Essential amino acid supplementation to fish meal-based diets with low protein to energy ratios improves the protein utilization in juvenile rainbow trout (O. mykiss). Aquaculture, 2005 (in press).

ZARATE, D.D.; LOVELL, R.T. Free lysine (L-lysine.HCl) is utilized for growth less efficiently than protein-bound lysine (soybean meal) in practical diets by young channel catfish (Ictalurus punctatus). Aquaculture, v.159, p.87-100, 1997. 